\title{
NATURAL AND MARANGONI CONVECTIONS IN A FLOATING ZONE
}

\author{
YASUNORI OKANO, AKo HATANO AND AKIRA HIRATA \\ Department of Chemical Engineering, Waseda University, Tokyo 169
}

Key Words: Fluid Mechanics, Floating Zone, Crystal Growth, Material, Marangoni Convection, Natural Convection, Interfacial Velocity, Order of Magnitude

\begin{abstract}
Using an order-of-magnitude evaluation, a quantitative evaluation was performed of the natural and Marangoni convections produced in the melt during single-crystal growth by the floating zone method.

The Reynolds number, which forms a standard for free interfacial velocity, was described as a function of the Grashof number, Marangoni number and Prandtl number. The results of this theoretical study showed good agreement with previous experimental works using model liquids and a glass melt.
\end{abstract}

\section{Introduction}

The floating zone method is a widely used technique for growing single crystals. When single crystals are grown by this method, natural and Marangoni convections are formed in the melt due to the temperature distribution, and have an important effect on the quality of the single crystals. For this reaon, much research has been carried out on the convection processes occurring in a floating zone, both in theoretical studies ${ }^{3-6)}$ and also in experimental work using model liquids ${ }^{1,7,10)}$ and a glass melt. ${ }^{8)}$ However, these works concentrated on the velocity and temperature distributions for convections in melts under certain growth conditions; there have been no reports regarding a quantitative evaluation of the relationship between single-crystal growth conditions and melt convection velocity.

The authors carried out a quantitative evaluation of the natural and Marangoni convections for the melt inside a two-dimensional rectangular open boat. ${ }^{9)}$ In this study, an order-of-magnitude evaluation ${ }^{9,11)}$ was performed for the Marangoni and natural convections in a floating zone, thus making possible a quantitative evaluation of the effect of natural and Marangoni convections on the interfacial velocity at the free interface.

\section{Configuration and Basic Equations}

A diagram of the theoretical model and the coordinate system are shown in Fig. 1. The following assumptions were made:

(1) the fluid is incompressible and Newtonian; (2) flow is steady, symmetrical and two-dimensional; (3) the free interface and the crystal-melt interface are

Received September 9, 1988. Correspondence concerning this article should be addressed to Y. Okano, Institute for Materials Research, Tohoku Univ., Sendai 980. both flat; (4) $T_{H}>T_{C}$; (5) there is no rotation or movement of the upper and lower rods; (6) the values of all phyical properties are constant except for the interfacial tension in the stress balance equation and the density in the buoyancy force term.

The basic equations are as follows:

Continuity equation

$$
\frac{1}{r} \frac{\partial}{\partial r}\left(r u_{r}\right)+\frac{\partial u_{z}}{\partial z}=0
$$

Navier-Stokes equations

$u_{r} \frac{\partial u_{r}}{\partial r}+u_{z} \frac{\partial u_{r}}{\partial z}=-\frac{1}{\rho} \frac{\partial p}{\partial r}+v\left[\frac{\partial}{\partial r}\left(\frac{1}{r} \frac{\partial}{\partial r}\left(r u_{r}\right)\right)+\frac{\partial^{2} u_{r}}{\partial z^{2}}\right]$

$u_{r} \frac{\partial u_{z}}{\partial r}+u_{z} \frac{\partial u_{z}}{\partial z}=-\frac{1}{\rho} \frac{\partial p}{\partial z}+v\left[\frac{1}{r} \frac{\partial}{\partial r}\left(r \frac{\partial u_{z}}{\partial r}\right)+\frac{\partial^{2} u_{z}}{\partial z^{2}}\right]$

$$
+g \beta\left(T_{H}-T_{C}\right)
$$

Energy equation

$$
u_{r} \frac{\partial T}{\partial r}+u_{z} \frac{\partial T}{\partial z}=\alpha\left[\frac{1}{r} \frac{\partial}{\partial r}\left(r \frac{\partial T}{\partial r}\right)+\frac{\partial^{2} T}{\partial z^{2}}\right]
$$

Stress balance equation (at $r=r_{c}$ )

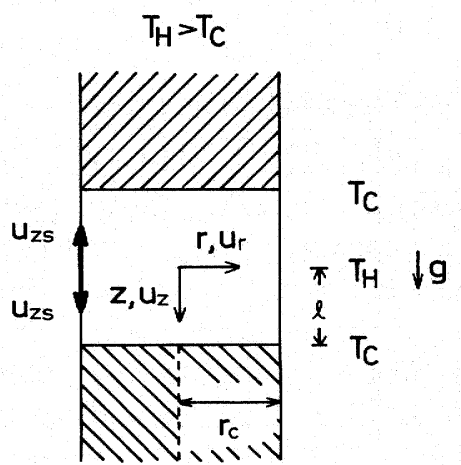

Fig. 1. Configuration for analysis and coordinate system 
Table 1. Results-of-Order-of-Magnitude Evaluation of Natural and Marangoni Convections in a Floating Zone

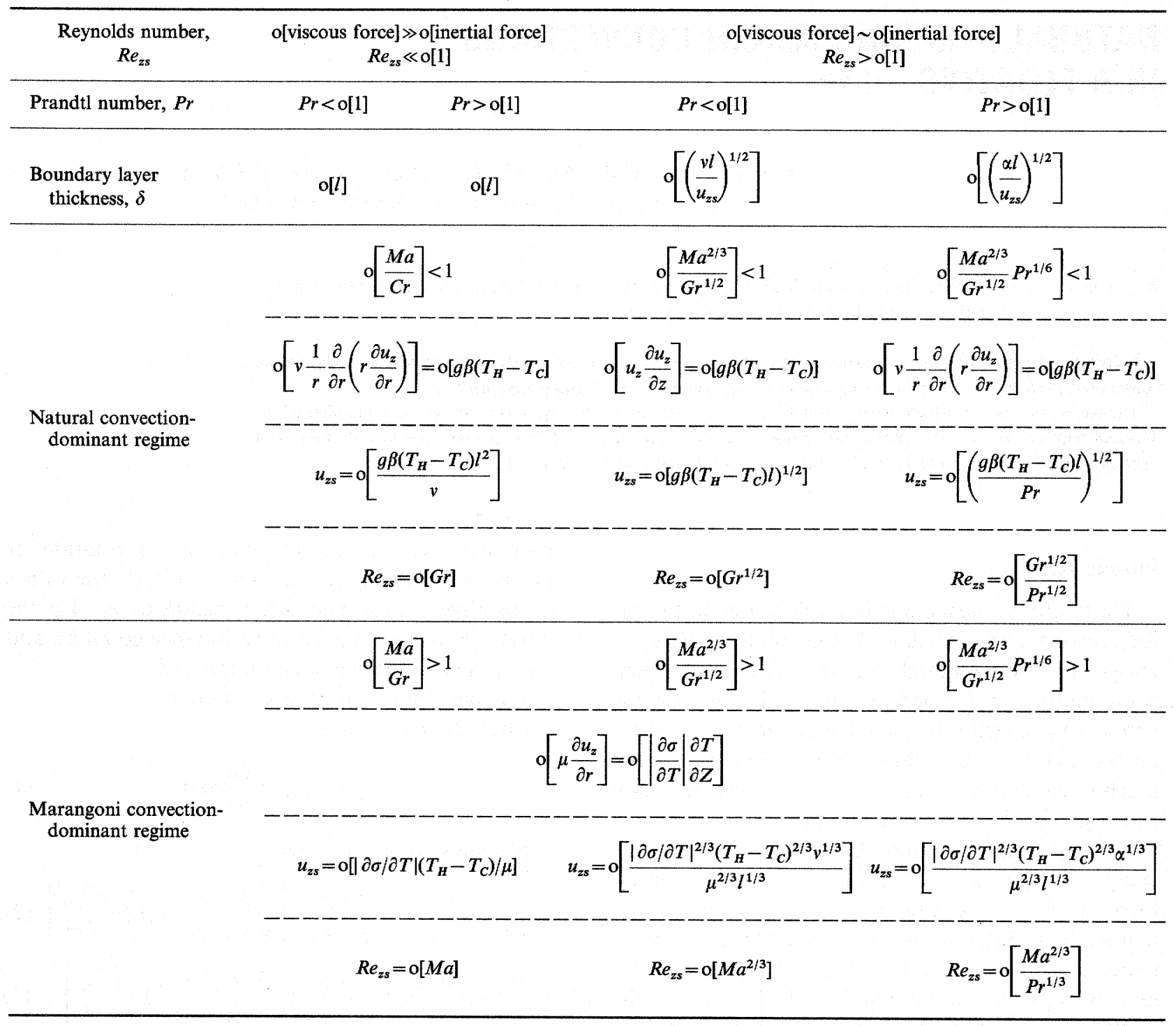

$$
\mu \frac{\partial u_{z}}{\partial r}=-\frac{\partial \sigma}{\partial T} \cdot \frac{\partial T}{\partial z}
$$

Using an order-of-magnitude evaluation for the equations above, ${ }^{9,11)}$ an evaluation was made of the effect of natural convection, Marangoni convection and Prandtl number on interfacial velocity at the free interface.

\section{Order-of-Magnitude Evaluation}

In Eqs. (1)-(5), $r$ and $\partial r$ were replaced by $\delta, \partial z$ by $l, u_{r}$ and $\partial u_{r}$ by $u_{r 0}, u_{z}$ and $\partial u_{z}$ by $u_{z 0}$ (although in Eq. (5), $\partial u_{z}$ was replaced by $\left.u_{z s}\right)$, and $\partial T$ by $\left(T_{H}-T_{C}\right)$, and an analysis was performed in the same manner as reported in the previous paper. ${ }^{9)}$ The results are shown in Table 1. In Table $1, M a / G r, M a^{2 / 3} / G r^{1 / 2}$ and $\mathrm{Pr}^{1 / 6} \mathrm{Ma}^{2 / 3} / \mathrm{Gr}^{1 / 2}$ are the parameters determining whether it is the natural or Marangoni convection that will have an effect on the interfacial velocity.
When the order of magnitude of these parameters is less than 1 , natural convection is dominant; conversely, when the value is greater than 1 , Marangoni convection is dominant. Also, when the order of magnitude of the parameters is approximately equal to 1 , the effects of natural and Marangoni convections on interfacial velocity are approximately equal. In previous research, comparisons of the buoyancy and thermocapillary forces, and the magnitudes of the natural and Marangoni convections, in a floating zone have been carried out using the following "dyanamic Bond number":2,7,10)

$$
B o=\rho g \beta L^{2} /|\partial \sigma / \partial T|=\left(M a_{L} / G r_{L}\right)^{-1}
$$

However, the results of the present study have shown that the "dynamic Bond number" can only be used to determine which melt convection is dominant when $R e_{z s} \ll \circ[1]$, and that when $R e_{z s} \gg$ o[1] the important parameters are $M a^{2 / 3} / G r^{1 / 2}$ and 


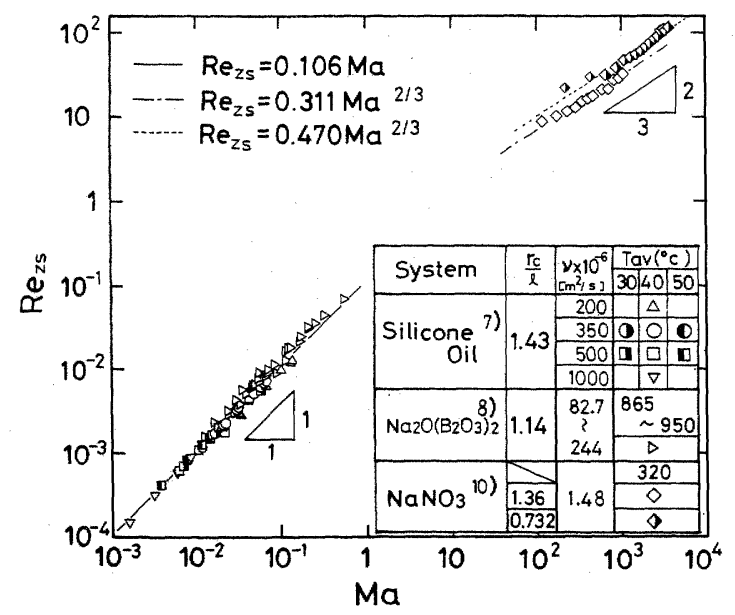

Fig. 2. Comparison of results in Table 1 with previous experimental results

$\operatorname{Pr}^{1 / 6} M a^{2 / 3} / G r^{1 / 2}$. In addition, it can be seen from Table 1 that when $R e_{z s} \geqq o[1]$ and also $P r>o[1]$, the interfacial velocity is a function not only of the Grashof and Marangoni numbers but also of the Prandtl number.

\section{Comparison with Previous Experimental Results}

Preisser et $_{\text {al }}{ }^{10)}$ and McNeil et al. ${ }^{7,8)}$ carried out experimental research on Marangoni convection in a vertical capillary liquid bridge using molten sodium nitrate, and silicone oils and molten sodium borate, respectively, and observed the interfacial velocity induced by Marangoni convection by means of a tracer technique. Their experimental results, after adjustment to comply with the form of the results of Table 1 , are shown in Fig. 2. Good agreement was obtained between the results shown in Table 1 and previous experimental results.

From Fig. 2 it was possible to determine the constants of proportionality for Table 1 , and as a result the following experimental equations were obtained:

When $R e_{z s} \ll \mathrm{o}[1]$,

$$
\begin{aligned}
& R e_{z s}=0.106 M a \\
& u_{z s}=0.106|\partial \sigma / \partial T|\left(T_{H}-T_{C}\right) / \mu
\end{aligned}
$$

When $\operatorname{Re}_{z s}>\mathrm{o}[1]$,

$$
\begin{aligned}
R e_{z s} & =0.470 M a^{2 / 3} \\
& =0.974 M a^{2 / 3} / \operatorname{Pr}^{1 / 3} \quad\left(r_{c} l=0.732\right) \\
u_{z s} & =0.974\left(\frac{|\partial \sigma / \partial T|\left(T_{H}-T_{C}\right) \alpha^{1 / 2}}{\mu l^{1 / 2}}\right)^{2 / 3}
\end{aligned}
$$

Also,

$$
\begin{aligned}
R e_{z s} & =0.311 M a^{2 / 3} \\
& =0.645 M a^{2 / 3} / \operatorname{Pr}^{1 / 3} \quad\left(r_{c} / l=1.36\right)
\end{aligned}
$$

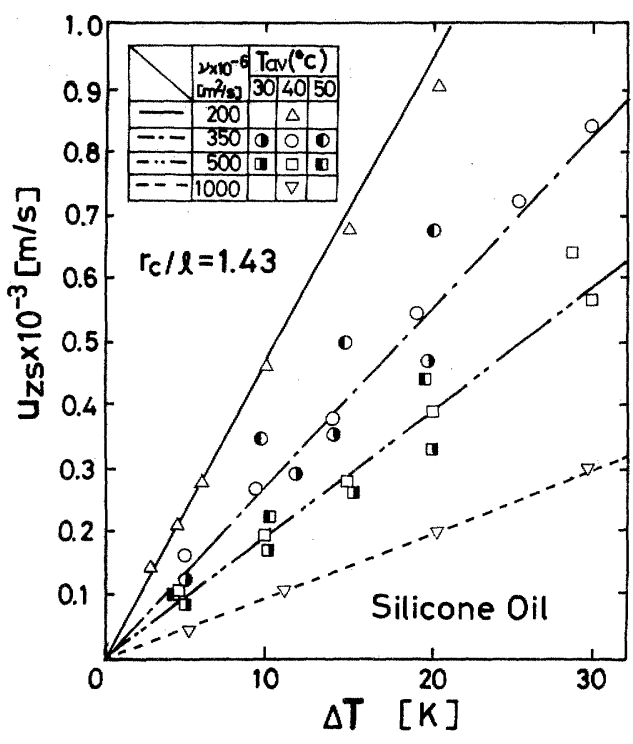

(a) McNeil et al?

Fig. 3(a). Interfacial velocity induced by Marangoni convection (comparison with experimental results by McNeil $e t$ al. ${ }^{7)}$ )

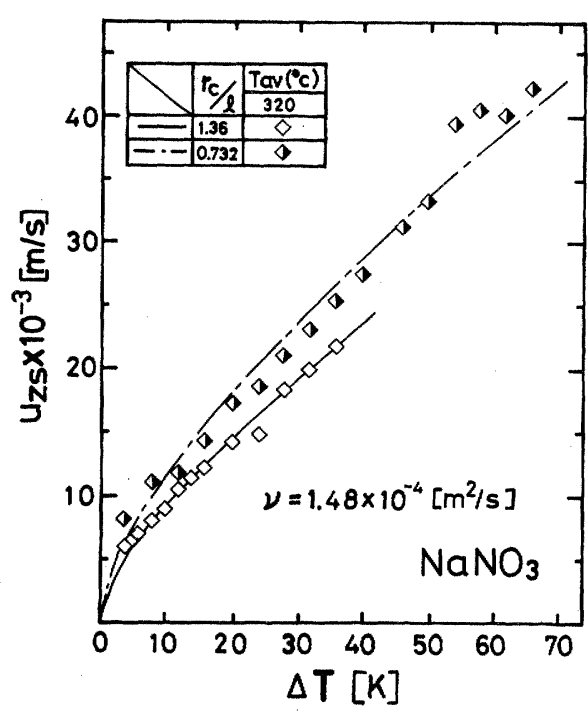

(b) Preisser et al. ${ }^{10)}$

Fig. 3(b). Interfacial velocity induced by Marangoni convection (comparison with experimental results by Preisser et al. ${ }^{10)}$ )

$$
u_{z s}=0.645\left(\frac{|\partial \sigma / \partial T|\left(T_{H}-T_{C}\right) \alpha^{1 / 2}}{\mu l^{1 / 2}}\right)^{2 / 3}
$$

Figure 3 shows the relationship between the interfacial velocity, $u_{z s}$, and the temperature difference, $\left(T_{H}-T_{C}\right)$. In Fig. 3, points represent previous experimental results and lines show the results given by Eqs. (8), (10), and (12). Figure 3(b) shows an interfacial velocity of approximately $20 \mathrm{~mm} / \mathrm{sec}$. when the temperature difference between the upper and lower rods is approximately $30 \mathrm{~K}$. Considering that the values of $l$ used in the experiments were $2.2 \mathrm{~mm}$ 
and $4.1 \mathrm{~mm}$, this is an extremely high velocity, and shows that the flow induced by Marangoni convection is extremely fast.

\section{Conclusion}

Using an order-of-magnitude evaluation of Marangoni and natural convections in a floating zone, the effects of the natural and Marangoni convections on interfacial velocity at the free interface were investigated. The theoretical results obtained showed good agreement with previous experimental results for Marangoni convection in a vertical capillary liquid bridge using model liquids and a glass melt.

\section{Acknowledgement}

This work was supported by Grant-in-Aid for General Scientific Research (No. 62470111) from the Ministry of Education, Science and Culture of Japan.

\section{Nomenclature}

\begin{tabular}{|c|c|c|}
\hline Bo & $=$ dynamic Bond number $\left(=\rho g \beta L^{2} /|\partial \sigma / \partial T|\right)$ & \\
\hline$g$ & $=$ gravitational acceleration & {$[\mathrm{m} / \mathrm{s}$} \\
\hline$G r$ & $=$ Grashof number $\left(=g \beta \Delta T l^{3} / v^{2}\right)$ & \\
\hline$G r_{L}$ & $=$ Grashof number $\left(=g \beta \Delta T L^{3} / v^{2}\right)$ & \\
\hline$L$ & $=$ reference length & \\
\hline$l$ & $\begin{array}{l}=\text { half-length of free interface of floating } \\
\text { zone }\end{array}$ & \\
\hline$M a$ & $=$ Marangoni number $(=|\partial \sigma / \partial T| \Delta T l /(\mu \cdot v))$ & \\
\hline$M a_{L}$ & $=$ Marangoni number $(=|\partial \sigma / \partial T| \Delta T L /(\mu \cdot v))$ & \\
\hline o & $=$ order & \\
\hline$p$ & $=$ pressure & \\
\hline $\operatorname{Pr}$ & $=$ Prandtl number $(=v / \alpha)$ & \\
\hline$r$ & $=$ radial coordinate & \\
\hline$r_{c}$ & $=$ radius of floating zone & \\
\hline $\operatorname{Re}$ & $=$ Reynolds number $(=u l / v)$ & \\
\hline$T$ & $=$ temperature & \\
\hline$u$ & $=$ velocity & \\
\hline
\end{tabular}

$\begin{array}{llr}u_{r 0} & =\text { reference velocity of } u_{r} & {[\mathrm{~m} / \mathrm{s}]} \\ u_{z o} & =\text { reference velocity of } u_{z} & {[\mathrm{~m} / \mathrm{s}]} \\ z & =\text { axial coordinate } & {[\mathrm{m}]} \\ \alpha & & \\ \beta & =\text { thermal diffusivity } & {\left[\mathrm{m}^{2} / \mathrm{s}\right]} \\ \delta & =\text { thermal expansion coefficient } & {[1 / \mathrm{K}]} \\ & =\text { thickness of boundary layer along a free } & \\ \mu & & \text { interface } \\ \nu & =\text { viscosity } & {[\mathrm{m}]} \\ \rho & =\text { kinematic viscosity } & {\left[\mathrm{m}^{2} / \mathrm{s}\right]} \\ \sigma & =\text { density } & {\left[\mathrm{kg} / \mathrm{m}^{3}\right]} \\ & =\text { interfacial tension } & {[\mathrm{N} / \mathrm{m}]}\end{array}$

$\langle$ Subscripts〉

$\begin{array}{ll}a v & =\text { average } \\ C & =\text { cold } \\ H & =\text { hot } \\ r & =\text { radial } \\ s & =\text { free interface } \\ z & =\text { axial }\end{array}$

\section{Literature Cited}

1) Change, C. E. and W. R. Wilcox: Int. J. Heat Mass Transfer, 19, 355 (1976).

2) Chun, Ch.-H.: J. Crystal Growth, 48, 600 (1980).

3) Kamotani, Y. and J. Kim: J. Crystal Growth, 87, 62 (1988).

4) Kobayashi, N.: J. Crystal Growth, 66, 63 (1984).

5) Kobayashi, N.: Japanese J. Appl. Phys., 27, 20 (1988).

6) Kozhoukharova, Zh. and S. Slavchev: J. Crystal Growth, 74, 236 (1986).

7) McNeil, T. J., R. Cole and R. S. Subramanian: J. Colloid and Interface Sci., 98, 210 (1984).

8) McNeil, T. J., R. Cole and R. S. Subramanian: J. Am. Ceram, Soc., 68, 254 (1985).

9) Okano, Y., M. Itoh and A. Hirata: J. Chem. Eng. Japan, 22, 275 (1989).

10) Preisser, F., D. Schwabe and A. Scharmann: J. Fluid Mech., 126, 545 (1983).

11) Ruckenstein, E.: AIChE J., 26, 850 (1980). 